\title{
Long-term Air Pollution Exposure Impact on COVID-19 Morbidity in China
}

Aerosol and Air Quality Research

Special Issue:

Special Issue on COVID-19 Aerosol Drivers, Impacts and Mitigation (IX)

\section{Yihan $\mathrm{Wu}^{1}$, Qingming Zhan ${ }^{{ }^{*}}$, Qunshan Zhao ${ }^{2}$}

\author{
${ }^{1}$ School of Urban Design, Wuhan University, Wuhan 430072, China \\ ${ }^{2}$ Urban Big Data Centre, School of Social and Political Sciences, University of Glasgow, Glasgow \\ G12 8RZ, UK
}

\section{ABSTRACT}

Although previous studies have proved the association between air pollution and respiratory viral infection, given the relatively short history of human infection with the severe acute respiratory syndrome coronavirus (SARS-CoV-2), the linkage between long-term air pollution exposure and the morbidity of 2019 novel coronavirus (COVID-19) pneumonia remains poorly understood. To fill this gap, this study investigates the influences of particulate matters $\left(\mathrm{PM}_{2.5}\right.$ and $\left.\mathrm{PM} \mathrm{M}_{10}\right)$, nitrogen dioxide $\left(\mathrm{NO}_{2}\right)$, ozone $\left(\mathrm{O}_{3}\right)$, sulfur dioxide $\left(\mathrm{SO}_{2}\right)$ and carbon monoxide $(\mathrm{CO})$ on COVID-19 incidence rate based on the prefecture-level morbidity count and air quality data in China. Annual means for ambient $\mathrm{PM}_{2.5}, \mathrm{PM}_{10}, \mathrm{SO}_{2}, \mathrm{NO}_{2}, \mathrm{CO}$ and $\mathrm{O}_{3}$ concentrations in each prefecture are used to estimate the population's exposure. We leverage identical statistical methods, i.e., Spearman's rank correlation and negative binomial regression model, to demonstrate that people who are chronically exposed to ambient air pollution are more likely to be infected by COVID-19. Our statistical analysis indicates that a $1 \mu \mathrm{g} \mathrm{m}^{-3}$ increase of $\mathrm{PM}_{2.5}, \mathrm{PM}_{10}$, $\mathrm{NO}_{2}$ and $\mathrm{O}_{3}$ can result in $1.95 \%$ (95\% Cl: $\left.0.83-3.08 \%\right), 0.55 \%$ (95\% Cl: $\left.-0.05-1.17 \%\right), 4.63 \%(95 \%$ $\mathrm{Cl}: 3.07-6.22 \%$ ) rise and $2.05 \%$ (95\% Cl: 0.51-3.59\%) decrease of COVID-19 morbidity. However, we observe nonsignificant association with long-term $\mathrm{SO}_{2}$ and $\mathrm{CO}$ exposure to COVID-19 morbidity in this study. Our results' robustness is examined based on sensitivity analyses that adjust for a wide range of confounders, including socio-economic, demographic, weather, healthcare, and mobility-related variables. We acknowledge that more laboratory results are required to prove the etiology of these associations.

Keywords: Air pollution exposure, COVID-19 morbidity, Prefecture-level data, Negative binomial regression

\section{INTRODUCTION}

In December 2019, the severe acute respiratory syndrome coronavirus (SARS-CoV-2), a novel virus identified as the pathogen of 2019 novel coronavirus (COVID-19) pneumonia, was detected (Li et al., 2020). As COVID-19 continued to take a heavy toll on countries around the world, the World Health Organization (WHO) declared it a Public Health Emergency of International Concern (WHO, 2020).

Recent virological assessments suggest that the pathophysiological mechanisms of SARS-CoV-2 are similar to that of SARS-CoV, where there is evidence to prove that both viruses predominantly infect airway and alveolar epithelial cells, vascular endothelial cells, and macrophages of humans (Zhao et al., 2020; Zhou et al., 2020). Some of the most common symptoms of COVID-19 are fever, cough, fatigue, and myalgia (Guan et al., 2020; Goyal et al., 2020; Young et al., 2020).

According to several reports on the clinical characteristics of the patients affected by COVID-19 in China and the United States, patients receiving invasive mechanical ventilation or presenting more severe symptoms are more likely to be male, to have obesity or to have some coexisting diseases such as hypertension, diabetes, chronic obstructive pulmonary disease, coronary heart disease, and cerebrovascular disease. (Guan et al., 2020; Goyal et al., 2020; Young et al., 2020). 
Besides, a few retrospective cohort studies point out that other risk factors, including but not limited to older age ( $\geq 65$ years old), smoking history, education level, and household income level, are likely to be associated with the clinical outcomes of COVID-19 (Engin et al., 2020; Liu et al., 2020; Wu et al., 2020).

China has suffered from extensive air pollution and subsequent severe outcomes in recent years. According to Song et al. (2017), in the year 2014 (2015, 2016), only 7\% (14\%, 19\%), 17\% $(27 \%, 34 \%), 51 \%(67 \%, 70 \%)$, and $88 \%(97 \%, 98 \%)$ of the population lived in areas where the annual $\mathrm{PM}_{2.5}, \mathrm{PM}_{10}, \mathrm{NO}_{2}$, and $\mathrm{SO}_{2}$ levels were below the guideline values specified by the Chinese Ambient Air Quality Standard (CAAQS) Grade II standards. Another research conducted by Zheng et al. (2018) concludes that $\mathrm{SO}_{2}, \mathrm{NO}_{x}, \mathrm{PM}_{10}$, and $\mathrm{PM}_{2.5}$ emissions are predominantly generated from industrial activities (i.e., $60 \%, 38 \%, 57 \%, 50 \%$, and $53 \%$ of total emissions), whereas the residential activities account for almost $40 \%$ of $\mathrm{CO}$ emissions. In addition to the primary pollutants, the intensive chemical reactions between oxides of $\mathrm{NO}_{x}$ and volatile organic compounds (VOCs) contribute to the mass amounts of secondary $\mathrm{PM}$ and $\mathrm{O}_{3}$ products. Fortunately, since the year 2013, with the implementation of China's Clean Air Action as well as a series of other effective strategic plans (e.g., desulfurization of coal-burning power plant, restrictions on private vehicle ownership, development of electric vehicles) (Jin et al., 2016), the year 2017 had seen $62 \%, 17 \%, 27 \%, 38 \%$, and $35 \%$ emission reductions of $\mathrm{SO}_{2}, \mathrm{NO}_{\mathrm{x}}, \mathrm{CO}, \mathrm{PM}_{10}$, and $\mathrm{PM}_{2.5}$, respectively, compared to the annual average emissions in 2010 (Zheng et al., 2018).

There are considerable epidemiological and pathophysiological evidence that link long-term air pollution exposure to many premature deaths and increased morbidity due to respiratory and cardiovascular diseases. A review by Hoek et al. (2013) summarizes the impacts of long-term exposure to $\mathrm{PM}_{2.5}, \mathrm{PM}$, nitrogen dioxide $\left(\mathrm{NO}_{2}\right)$, and elemental carbon on all-cause mortality and mortality induced by cardiovascular disease and respiratory disease. Their pool effect estimation based on meta-analysis exhibits that a $10 \mu \mathrm{g} \mathrm{m}^{-3}$ increase of $\mathrm{PM}_{2.5}$ may lead to $6 \%$ (95\% Cl: 4$8 \%), 11 \%(95 \% \mathrm{Cl}: 5-16 \%)$ and $3 \%(95 \% \mathrm{Cl}:-6-13 \%)$ rise of the percent excess risk for all-cause, cardiovascular and non-malignant respiratory mortality, respectively. Further, Pope et al. (2004)'s research based on the data of Cancer Prevention Study II collected by American Cancer Society confirms that a $10 \mu \mathrm{g} \mathrm{m}^{-3}$ growth of $\mathrm{PM}_{2.5}$ is associated with $8 \%$ to $18 \%$ increases in death risk of numerous cardiopulmonary diseases, e.g., ischemic heart disease, dysrhythmias, heart failure, and cardiac arrest. Lipfert (2018) assessed 417 long-term studies on the association of morbidity with air pollution (exposure duration varies between 60 days and 35 years) and found that 224 of them report significant exposure-outcome relationships and 220 reveal adverse effects. Besides, Lipfert's (2018) study suggests that $\mathrm{PM}_{2.5}, \mathrm{O}_{3}, \mathrm{NO}_{2}$, and $\mathrm{PM}_{10}$ are more likely to cause cardiovascular, respiratory, neurological, and birth/pregnancy outcomes, respectively.

While substantial heterogeneity of the impacts that air pollution exerts on human health is found across various studies, there is a consensus that suspended fine particles, nitrogen dioxide, ozone, carbon monoxide and sulfur dioxide may incase the risk of acute respiratory disease, or expedite the development of atherosclerosis and cardiovascular disease through multiple pathophysiological pathways (Brook et al., 2004; Pope et al., 2004). Also, we found that the effect estimation of pollutants can be modified by a broad spectrum of factors, such as population characteristics, human behavioral patterns, methodology applied for exposure-outcome assessment, regional-specific variations, and confounding effect, etc. (Hoek et al., 2013; Lipfert, 2018; Wu et al., 2020).

Moreover, since the outbreak of COVID-19, several epidemiological studies have been initiated globally, utilizing various investigation methods such as cross-sectional analysis and time-series analysis. A research team found that a $1 \mu \mathrm{g} \mathrm{m}^{-3}$ increase of $\mathrm{PM}_{2.5}$ is associated with a $15 \%$ increase of COVID-19 mortality rate, as revealed by a cross-sectional analysis using county-level data in the United States (Wu et al.,2020). Also, Ogen (2020)'s spatial analysis shows that the hot spots of high-level $\mathrm{NO}_{2}$ concentrations correspond to areas with high fatality rates in Europe. Furthermore, Zhu et al. (2020) investigated the impacts of short-term air pollution exposure on COVID-19 infection, under the assumption that SARS-CoV-2 can be transmitted by aerosols and may pose an inhalation threat. Their results suggest a $10 \mu \mathrm{g} \mathrm{m}^{-3}$ increase of $\mathrm{PM}_{2.5}, \mathrm{PM}_{10}, \mathrm{NO}_{2}$ and $\mathrm{O}_{3}$ is associated with a $2.24 \%(95 \% \mathrm{Cl}: 1.02-3.46), 1.76 \%(95 \% \mathrm{Cl}: 0.89-2.63), 6.94 \%(95 \% \mathrm{Cl}$ : 2.38-11.51), 4.76\% (95\% Cl: 1.99-7.52) increase of COVID-19 morbidity rate, respectively.

In a nutshell, the above observations support the hypothetical correlation between COVID-19 
infection and prolonged air pollution exposure. However, to what extent does the long-term air pollution exposure affect COVID-19 morbidity is unclear. Since persisted exposure to various air pollutants can induce airway inflammation, worsen pulmonary function and gas exchange and cause cardiovascular dysfunctions (Grunig et al., 2014; Jiang et al., 2016; Contini and Costabile, 2020), in this study, we hypothesize that these mechanisms will also have detrimental impacts on the vulnerability of the population to COVID-19. Hence, the overarching goal of this study is to understand the potential relationships between COVID-19 morbidity count and long-term air pollution exposure in the prefecture level. Accordingly, we employed several statistical methods to examine the systemic effects of air pollution exposure on COVID-19 morbidity, and applied sensitivity analyses to verify our conclusions' robustness.

\section{STUDY AREA AND DATA}

Our study area includes 326 prefectures in mainland China (Fig. 1). A few prefectures in Tibet and Xinjiang were omitted from our investigation because some confounder variables are not available in these regions (e.g., census data, air quality data). As of April 21, 2020, 82,788 confirmed cases were reported by the Chinese Center for Disease Control and Prevention (China CDC), including the number of COVID-19 infections in Hong Kong, Macao, and Taiwan.

The COVID-19 morbidity data was obtained from the public reports published by China CDC. While the air quality data, consisting of $\mathrm{PM}_{2.5}, \mathrm{PM}_{10}, \mathrm{NO}_{2}, \mathrm{SO}_{2}, \mathrm{CO}$ and $\mathrm{O}_{3}$, was derived from national air quality monitoring site network of the Ministry of Environmental Protection (MEP) (MEP, 2020). Although MEP began to grant access to air quality data since 2013, the data from 1494 sites in 367 prefectures became publicly available until 2015. Moreover, since these monitoring stations are mandated not to be in the direct vicinity of noticeable emission sources, such as major thoroughfares, the data is believed to be a good indication of the general air quality level in each prefecture. The air pollution exposure level was therefore estimated by averaging the daily concentrations of $\mathrm{PM}_{2.5}, \mathrm{PM}_{10}, \mathrm{NO}_{2}, \mathrm{SO}_{2}, \mathrm{CO}$, and $\mathrm{O}_{3}$ based on the monitored observations from 2015 to 2019.

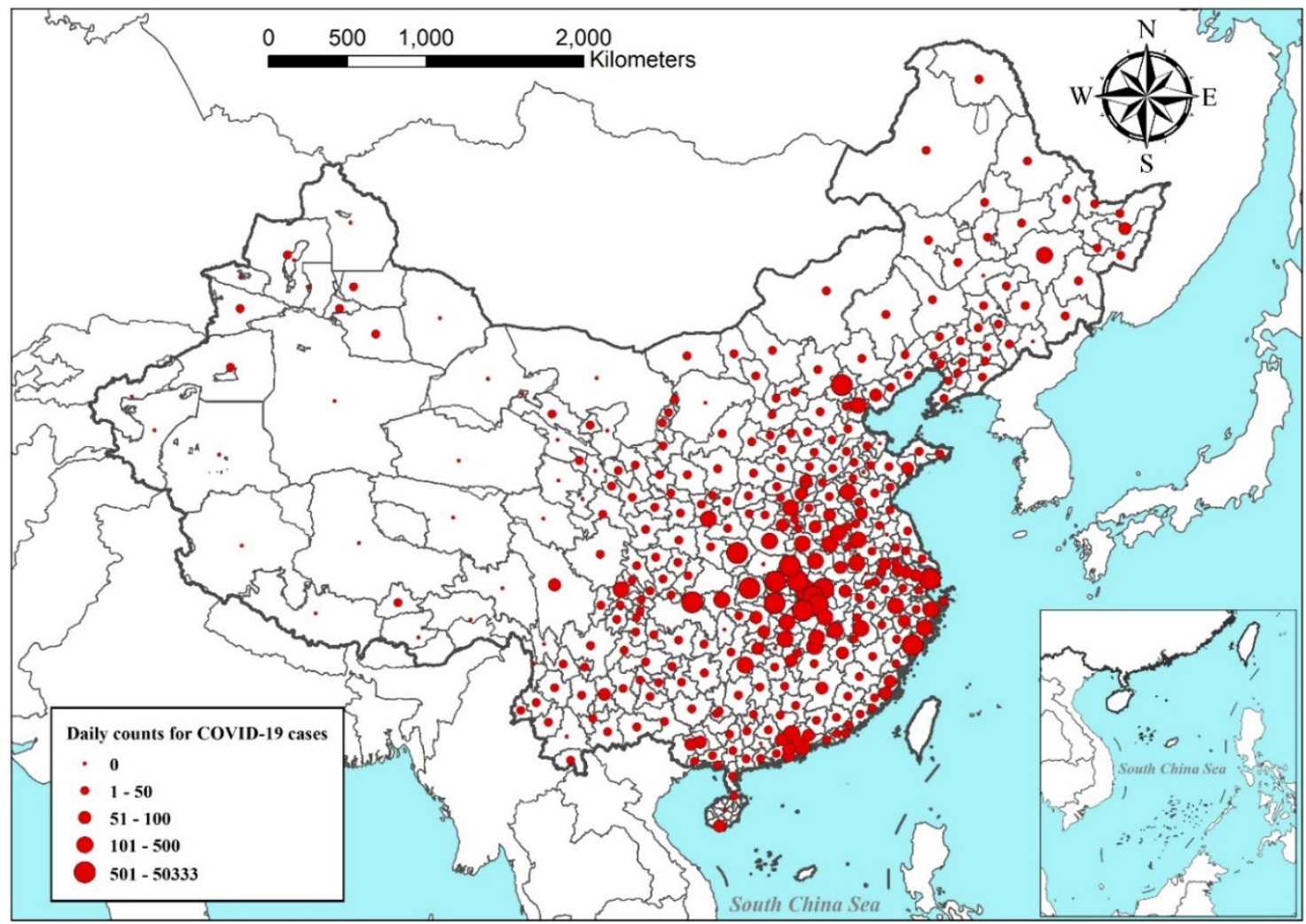

Fig. 1. The spatial distribution of COVID-19 confirmed cases in China (data until April 21, 2020). 
To account for the effects of confounding factors, we collected the demographic information from 2010 census results, such as population size, percentage of male/female population, percentage of people over 65 years old, and percentage of residents with a college degree (NBS, 2012). Also, a few socio-economic variables that represent the income level (i.e., per capita GDP, average wage) of the whole population in different cities in year 2017, were obtained from China City Statistical Yearbook 2018 (NBS, 2018). Since medical condition and health risk factors can determine whether people are susceptible to cardiopulmonary diseases, we retrieved the prefecture-level counts of doctors from the Statistical Yearbook and derived the smoking population data from a health survey conducted by Wang et al. (2019) in 31 provinces in 2010. Moreover, we averaged the daily air temperature, daily dew point temperature, and daily wind speed for summer (June to August) and winter (December to February) during the period 20152019 using record temperature and wind speed data provided by National Centers for Environmental Information of the United States (NCEI, 2020), and weather variables from 397 ground stations were then aggregated into prefecture-level values for the analysis.

Furthermore, to elaborate on the influences of mobility on the spread of the disease, we collected the population outflow data of Wuhan city from January 1 to January 22 before the city's lockdown. The data was obtained from the Baidu migration server, an online platform that traces the daily travelers in and out of different cities using their digital footprints (Baidu Inc, 2020). Additionally, the migration server offers the intra-city mobility index that measures the intensity of traveling activities within different cities' administrative boundaries. We calculated two cumulative mobility indicators from the migration data: one is the total population migrated from Wuhan before January 23 , and the other represents the cumulated intra-city movement in each prefecture before the lockdown.

\section{METHODS}

In this analysis, we fitted the negative binomial regression using prefecture-level morbidity count data as the dependent variable and prefecture-level long term air quality indicators as the exposure.

The negative binomial regression model (NB model) is one of the most popular regression methods applied for over-dispersed count data. The NB model can be considered as a generalized form of the Poisson regression model, despite that it supposes the conditional variance of the dependent variable is larger than its mean (Hilbe, 2011). The NB model allows one to describe a dependent variable using any number of independent variables and can be written as

$\mu(x)=\exp \left[\beta_{0}+\sum_{i=1}^{n} \beta_{i} x_{i}+\varepsilon\right]$

where $\mu(x)$ is the expected value of the response, $\beta_{i}$ is the estimated coefficient for the explanatory variable $x_{i}$ and can be derived through a maximum likelihood approach. $\beta_{0}$ denotes the intercept, and $\varepsilon$ is the residual term. More details about the NB model can be found in supplementary materials.

We excluded the Wuhan city from our samples since Wuhan was the epicenter of the outbreak and had witnessed overwhelmed COVID-19 cases. That said, the inclusion of the confirmed cases in Wuhan might over-represent the real risks of chronic exposure to ambient air pollution. Moreover, a few covariates were introduced into the model to adjust for the confounding effects of our model estimation. The selection of confounders was based on the existing literatures that report causal influences of extraneous variables on both exposure and response (Hoek et al., 2013; Lipfert, 2018; Wu et al., 2020).

Our NB regression model is therefore formulated as

$\log E\left(C_{i}\right)=\beta_{0}+\beta_{1} p o l+\beta_{2} d e n+\beta_{3} \mathrm{col}+\beta_{4} \mathrm{old}+\beta_{5} \mathrm{mal}+\beta_{6} \mathrm{Lgdp}+\beta_{7} \mathrm{Lwag}+\beta_{8} \mathrm{doc}+\beta_{9} \mathrm{smo}+\beta_{10 \mathrm{Sat}}$

$+\beta_{11} w a t+\beta_{12} s d t+\beta_{13} w d t+\beta_{14} s w s+\beta_{15} w w s+\beta_{16} m o v+\beta_{17 i c m}+\varepsilon_{i}$

The definition of independent and dependent variables can be found in nomenclature (Table 1). 
Denote $\log E\left(C_{i}\right)$ as the log transform of confirmed cases in prefecture $i$, hence, for each unit increase in a predictor, the expected log count of the COVID-19 infection cases is changed by the respective regression coefficient, holding other predictors as constants. The COVID-19 incidence rate ratio (IRR) is a natural exponential function of the regression coefficient $\beta_{i}\left(\exp \beta_{i}\right)$, which can be interpreted as the relative increase of COVID-19 morbidity rate associated with one unit increase of the pollutant (see supplementary materials).

The impacts of five air pollutants on COVID-19 morbidity were examined separately using 5 single-pollutant models, because previous studies indicate air pollutants can react with each other and their concentrations are often highly correlated (Wang et al., 2017; Chen et al., 2020), thereby inducing serious multicollinearity problems that may inflate the estimation of regression coefficients.

We carried out several sensitivity analyses to verify the robustness of our regression outcomes. First, we excluded all prefectures in Hubei province since their daily counts of COVID-19 were remarkably higher than others. Second, we computed the biasing effect of confounding on point and confidence interval estimates by individually omitting the following variables from our regression model: weather factors, income level, percent of population over 65 years old, number of doctors in each prefecture, and mobility indices. Third, we modelled the exposureoutcome relationship using the Poisson regression model as an alternative to evaluate the impact of modelling choice. Finally, instead of single-pollutant models, we employed the two-pollutant models to examine the significance of pollutants, in which two air pollutants were incorporated into the regression model to account for their covariance. All analyses were performed with $\mathrm{R}$ software, version 3.6.2.

\section{RESULTS}

\subsection{Characteristics of the COVID-19 Morbidity Distribution and Mean Air Pollution Levels in China}

A total of 29,936 confirmed cases were reported in 326 prefectures (excluding Wuhan) up to April 21, 2020. In Fig. 1, we plotted the geographic distributions of all cases registered in our study area and found that most COVID-19 patients were either located in the east coast or in areas that shared geographical proximities with Wuhan (e.g., Chongqing, Zhengzhou, and other cities in Hubei province). Similarly, people experienced the burden of ambient air pollutions

Table 1. The independent variables and their definitions.

\begin{tabular}{ll}
\hline Dependent variable & \\
\hline$E\left(C_{i}\right)$ & The expected COVID-19 morbidity count in prefecture $i$ \\
\hline Independent variables & \\
\hline pol & Average concentration of pollutant \\
col & Population density \\
old & Percentage of population with a college degree \\
mal & Percent population over 65 years old \\
Lgdp & Percent of males \\
Lwag & Log transform of Per capita GDP \\
doc & Log transform of Worker' s average wage \\
smo & Number of doctors in prefecture i/ total population \\
sat & Percent of the smoking population) \\
$w a t$ & Mean summer air temperature \\
sdt & Mean winter air temperature \\
$w d t$ & Mean summer dew point temperature \\
sws & Mean winter dew point temperature \\
$w w s$ & Mean summer wind speed \\
mov & Mean winter wind speed \\
$i c m$ & Total population migrated from Wuhan before lockdown \\
\hline
\end{tabular}


disproportionately (Fig. S1), with most of them living in cities that encompassed a large portion of manufacturing industries (e.g., Beijing-Tianjin-Hebei region).

The mean and standard error for the five-year air pollution concentration levels are reported in Table 2, of which the average concentrations of $\mathrm{PM}_{2.5}, \mathrm{PM}_{10}, \mathrm{O}_{3}, \mathrm{SO}_{2}, \mathrm{NO}_{2}$, and $\mathrm{CO}$ were 43.53 $\mu \mathrm{g} \mathrm{m}^{-3}, 77.68 \mu \mathrm{g} \mathrm{m}^{-3}, 18.56 \mu \mathrm{g} \mathrm{m}^{-3}, 29.39 \mu \mathrm{g} \mathrm{m}^{-3}, 60.04 \mu \mathrm{g} \mathrm{m}^{-3}$, and $0.95 \mathrm{mg} \mathrm{m}^{-3}$, respectively. The thresholds for annual mean concentrations of $\mathrm{PM}_{2.5}, \mathrm{PM}_{10}$, and $\mathrm{NO}_{2}$ were specified as $10 \mu \mathrm{g} \mathrm{m}^{-3}, 20 \mu \mathrm{g} \mathrm{m}^{-3}$, and $40 \mu \mathrm{g} \mathrm{m}^{-3}$, respectively by WHO in its air pollution risk assessment report (only short-term concentration thresholds are available for $\mathrm{O}_{3}, \mathrm{SO}_{2}$, and $\mathrm{CO}$, so we did not include them here), to mitigate detrimental health impacts on humans (WHO, 2006). Based on the five-year air quality observations, almost all air quality indicators had exceeded WHO's guideline values for individual substances. Therefore, we believed the deteriorated air quality had already posed significant threats to the well-being of the population in China.

\subsection{Relation between Long-term Air Pollution Exposure and COVID-19 Morbidity}

We performed a Spearman's rank correlation test to evaluate the bivariate associations between air pollutant concentrations and prefecture-level COVID-19 morbidity counts (Table 3). As suggested by this preliminary analysis, $\mathrm{PM}_{2.5}, \mathrm{PM}_{10}, \mathrm{SO}_{2}, \mathrm{NO}_{2}$, and $\mathrm{CO}$ were strongly correlated,

Table 2. Statistics summary of air quality, weather, demographic, economic, medical condition and mobility data for 326 prefectures in China.

\begin{tabular}{|c|c|c|c|}
\hline & Mean (SD) & Min & Max \\
\hline \multicolumn{4}{|l|}{ Air pollution data (2015-2019) } \\
\hline $\mathrm{PM}_{2.5}\left(\mu \mathrm{g} \mathrm{m}^{-3}\right)$ & $43.53(15.49)$ & 11.35 & 112.12 \\
\hline $\mathrm{PM}_{10}\left(\mu \mathrm{g} \mathrm{m}^{-3}\right)$ & $77.68(33.63)$ & 17.62 & 335.04 \\
\hline $\mathrm{SO}_{2}\left(\mu \mathrm{g} \mathrm{m}^{-3}\right)$ & $18.56(9.69)$ & 3.37 & 60.24 \\
\hline $\mathrm{NO}_{2}\left(\mu \mathrm{g} \mathrm{m}^{-3}\right)$ & $29.39(9.77)$ & 9.99 & 55.63 \\
\hline $\mathrm{O}_{3}\left(\mu \mathrm{g} \mathrm{m}^{-3}\right)$ & $60.04(9.66)$ & 34.90 & 101.29 \\
\hline $\mathrm{CO}\left(\mathrm{mg} \mathrm{m}^{-3}\right)$ & $0.95(0.27)$ & 0.44 & 2.02 \\
\hline \multicolumn{4}{|l|}{ Demographic data (2010) } \\
\hline Percent of males (\%) & $0.52(0.27)$ & 0.01 & 5.18 \\
\hline Percent population over 65 years old (\%) & $0.09(0.02)$ & 0.01 & 0.17 \\
\hline Percentage of population with a college degree (\%) & $0.08(0.05)$ & 0.00 & 0.47 \\
\hline Population density (people $\mathrm{km}^{-2}$ ) & $399.65(502.92)$ & 0.81 & 5304.04 \\
\hline \multicolumn{4}{|l|}{ Economic data (2017) } \\
\hline Per capita GDP (yuan) & $55053.45(32256.16)$ & 11786 & 183127 \\
\hline Worker's average wage (yuan) & $65611.36(13071.87)$ & 38713 & 134994 \\
\hline \multicolumn{4}{|l|}{ Medical condition data (2017) } \\
\hline Number of doctors per 1000 people & $2.52(0.93)$ & 0.13 & 10.12 \\
\hline \multicolumn{4}{|l|}{ Health risk data (2010) } \\
\hline Percent of smokers (provincial level) & $0.25(0.04)$ & 0.16 & 0.35 \\
\hline \multicolumn{4}{|l|}{ Weather data (2015-2019) } \\
\hline Mean summer air temperature $\left({ }^{\circ} \mathrm{C}\right)$ & $18.97(4.85)$ & 3.65 & 26.65 \\
\hline Mean summer dew point temperature $\left({ }^{\circ} \mathrm{C}\right)$ & $12.61(6.2)$ & -5.14 & 22.70 \\
\hline Mean summer wind speed $\left(\mathrm{m} \mathrm{s}^{-1}\right)$ & $2.37(0.82)$ & 1.18 & 6.61 \\
\hline Mean winter air temperature $\left({ }^{\circ} \mathrm{C}\right)$ & $1.65(9.02)$ & -24.32 & 20.77 \\
\hline Mean winter dew point temperature $\left({ }^{\circ} \mathrm{C}\right)$ & $-5.38(10.51)$ & -29.54 & 17.15 \\
\hline Mean winter wind speed $\left(\mathrm{m} \mathrm{s}^{-1}\right)$ & $2.42(0.93)$ & 1.02 & 7.22 \\
\hline \multicolumn{4}{|l|}{ Mobility data (2020) } \\
\hline $\begin{array}{l}\text { The cumulative index for total population migrated from } \\
\text { Wuhan before lockdown }\end{array}$ & $0.38(1.74)$ & 0.00 & 18.87 \\
\hline The cumulative index for intra-city movement before January 23 & $113.89(13.51)$ & 57.26 & 144.17 \\
\hline \multicolumn{4}{|l|}{ COVID-19 morbidity data (2020) } \\
\hline Prefecture-level daily counts for COVID-19 confirmed cases & $91.83(315.17)$ & 0 & 3518 \\
\hline
\end{tabular}


Table 3. Matrix of Spearman's rank correlation coefficient $(r)$ between mean daily concentration of pollutants and COVID-19 morbidity counts.

\begin{tabular}{llllllll}
\hline & $\mathrm{PM}_{2.5}$ & $\mathrm{PM}_{10}$ & $\mathrm{SO}_{2}$ & $\mathrm{NO}_{2}$ & $\mathrm{O}_{3}$ & $\mathrm{CO}$ & COVID-19 morbidity counts \\
\hline $\mathrm{PM}_{2.5}$ & - & $0.88^{* *}$ & $0.52^{* *}$ & $0.76^{* *}$ & $0.20^{* *}$ & $0.64^{* *}$ & $0.35^{* *}$ \\
$\mathrm{PM}_{10}$ & $0.88^{* *}$ & - & $0.61^{* *}$ & $0.72^{* *}$ & $0.33^{* *}$ & $0.62^{* *}$ & $0.15^{* *}$ \\
$\mathrm{SO}_{2}$ & $0.52^{* *}$ & $0.61^{* *}$ & - & $0.44^{* *}$ & $0.25^{* *}$ & $0.51^{* *}$ & -0.04 \\
$\mathrm{NO}_{2}$ & $0.76^{* *}$ & $0.72^{* *}$ & $0.44^{* *}$ & - & 0.06 & $0.56^{* *}$ & $0.37^{* *}$ \\
$\mathrm{O}_{3}$ & $0.20^{* *}$ & $0.33^{* *}$ & $0.25^{* *}$ & 0.06 & - & -0.04 & -0.02 \\
$\mathrm{CO}$ & $0.64^{* *}$ & $0.62^{* *}$ & $0.51^{* *}$ & $0.56^{* *}$ & -0.04 & - & $0.13^{*}$ \\
\hline
\end{tabular}

$* \mathrm{p}$ value $<0.05, * * \mathrm{p}$ value $<0.01$

whereas $\mathrm{O}_{3}$ shared relatively weak correlations with other pollutants. And the strongest correlations were observed for $\mathrm{PM}_{2.5}$ and $\mathrm{PM}_{10}(r=0.88)$, and $\mathrm{PM}_{2.5}$ and $\mathrm{NO}_{2}(r=0.76)$. Of all air pollutants examined, only $\mathrm{PM}_{2.5}(r=0.35)$ and $\mathrm{NO}_{2}(r=0.37)$ showed moderate correlations with COVID-19 morbidity.

\subsection{The Effect of Prolonged Air Pollution Exposure on COVID-19 Morbidity}

Fig. 2 and Table S1 conclude how various air pollutant concentrations influence the incidence rate of COVID-19 in China. With long-term air pollution exposure level measured as five-year average concentration of $\mathrm{PM}_{2.5}, \mathrm{PM}_{10}, \mathrm{NO}_{2}$, and $\mathrm{O}_{3}$, our regression outcomes addressed that a $1 \mu \mathrm{g} \mathrm{m}^{-3}$ increase of $\mathrm{PM}_{2.5}, \mathrm{PM}_{10}, \mathrm{NO}_{2}$, and $\mathrm{O}_{3}$ was correlated to $1.95 \%$ (95\% Cl: $0.83-3.08 \%$ ), $0.55 \%$ (95\% Cl: $-0.05-1.17 \%$ ), and $4.63 \%$ (95\% Cl: 3.07-6.22\%) increase and $2.05 \%$ (95\% Cl: $0.51-$ $3.59 \%)$ decrease of COVID-19 morbidity counts. While $\mathrm{PM}_{2.5}, \mathrm{PM}_{10}$, and $\mathrm{NO}_{2}$ were significantly positively associated with IRR, our results showed an interesting negative and statistically significant correlation between $\mathrm{O}_{3}$ and COVID-19 infection rate. Nonetheless, the regression analysis also indicated that the effects of $\mathrm{CO}$ and $\mathrm{SO}_{2}$ on COVID-19 morbidity were insignificant.

\subsection{Examination of Confounding Effects}

We omitted several confounders individually from the predictor set to elucidate their impacts on coefficient estimation. As demonstrated in Fig. 2, the effect estimation results remained consistent with our main analysis after separately controlling for various socio-economic, meteorological and demographic factors. However, interestingly, we observed a $1 \mu \mathrm{g} \mathrm{m}^{-3}$ increase of $\mathrm{PM}_{2.5}$ and $\mathrm{NO}_{2}$ would lead to much lower COVID-19 morbidity (IRR for $\mathrm{PM}_{2.5}$ was $1.01,95 \% \mathrm{Cl}: 1.00-1.02$, and IRR for $\mathrm{NO}_{2}$ was $1.03,95 \% \mathrm{Cl}$ : 1.01-1.05) when historical weather data was omitted from the analysis, which suggested weather variables were strong confounders that could markedly alter our statistical inferences. Another disparity was found when prefectures in Hubei were removed from the sampling dataset. The IRR changes associated with $\mathrm{PM}_{2.5}, \mathrm{PM}_{10}$, and $\mathrm{NO}_{2}$ moderately reduced from $1.95 \%, 0.55 \%$ and $4.63 \%$ to $1.43 \%, 0.47 \%$ and $4.09 \%$ when high leverage daily counts were excluded, implying the impacts of influential outliers. Further, our results indicated that the magnitude of regression coefficients was somewhat confounded by the presence of mobility variables, specifically the outflow population from Wuhan before the city's lockdown.

\subsection{Regression Analysis Results for Two-pollutant Models}

The two-pollutant models illustrated the exposure-outcome relationship when two pollutants were synthetically considered in our regression analysis (Fig. 3 and Table S2). Specifically, the association between $\mathrm{PM}_{2.5}$ and COVID-19 morbidity count was positive and significant, except when adjusting for $\mathrm{NO}_{2}$. For $\mathrm{PM}_{10}$, a $1 \mu \mathrm{g} \mathrm{m}^{-3}$ increase of the particulate matter was often associated with minor increase of COVID-19 morbidity, however, this relation was reversed when $\mathrm{NO}_{2}$ and $\mathrm{PM}_{2.5}$ were added to the model. The effect of $\mathrm{NO}_{2}$ was amplified and its correlation with COVID-19 morbidity remained significant in the presence of all the other pollutants. Comparing to the single-pollutant model result, the negative correlation between $\mathrm{O}_{3}$ and COVID-19 morbidity in the two-pollutant model retained its statistical significance, with little fluctuation of regression coefficients. Not surprisingly, when adjusting for other pollutants, we found generally positive but insignificant correlations between $\mathrm{SO}_{2}, \mathrm{CO}$ and COVID-19 morbidity. 

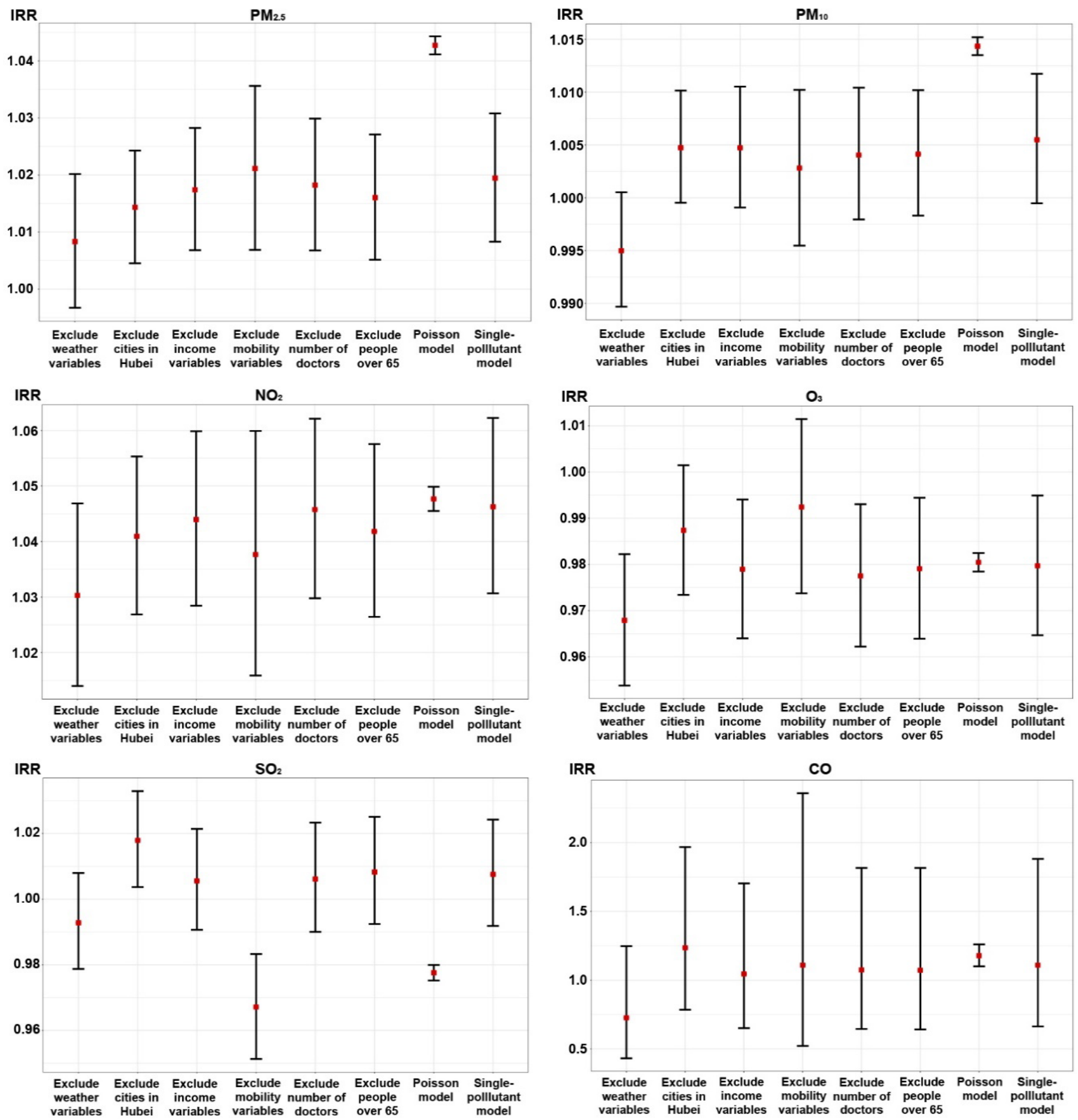

Fig. 2. The incidence rate ratio and $\mathrm{Cl}(95 \%)$ of COVID-19 morbidity associated with per $\mu \mathrm{g} \mathrm{m}^{-3}$ increase of $\mathrm{PM}_{2.5}, \mathrm{PM}_{10}, \mathrm{NO}_{2}, \mathrm{CO}$, $\mathrm{SO}_{2}$ and $\mathrm{O}_{3}$ using single-pollutant model, results were adjusted for weather, demographic, income, mobility and medical condition variables and Poisson regression model

\subsection{Examination of Modeling Choice}

Our statistical analysis showed that the prefecture-level morbidity count data had a variance of 99332.13 and a mean value of 91.83 (Table 2), and the estimated overdispersion parameter for the quasi-Poisson regression was 108.46 in the single-pollutant model for $\mathrm{PM}_{2.5}$, all of which suggested a compelling sign of overdispersion.

Additionally, we regressed the COVID-19 morbidity counts on air pollution exposure using the Poisson model, and the results indicated that the Poisson model tended to inflate the regression 

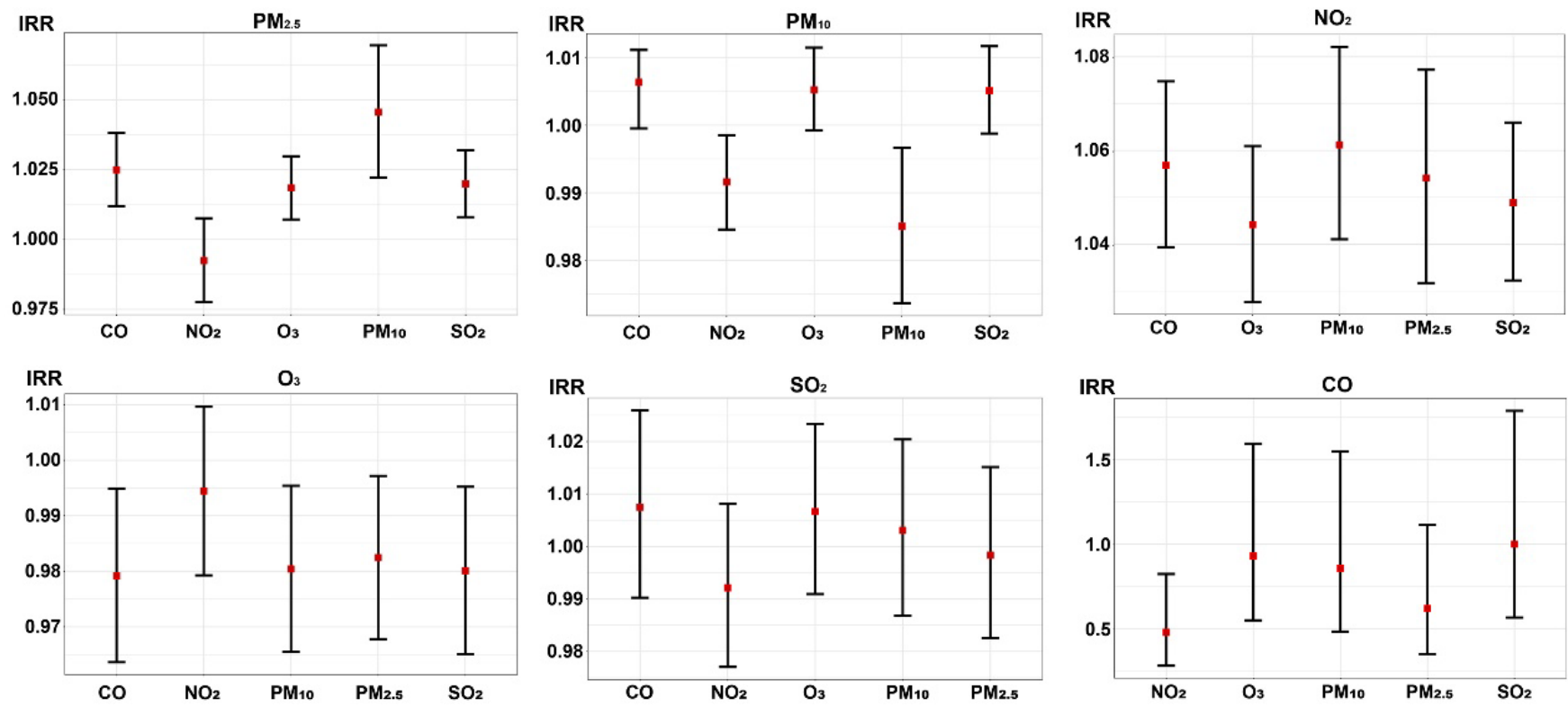

Fig. 3. The two-pollutant model results for COVID-19 incidence rate ratio and $\mathrm{Cl}(95 \%)$ associated with per $\mu \mathrm{g} \mathrm{m}^{-3}$ increase of $\mathrm{PM}_{2.5}, \mathrm{PM}_{10}, \mathrm{NO}_{2}, \mathrm{CO}, \mathrm{SO}_{2}$, and $\mathrm{O}_{3}$.

coefficients of pollutants (Table S1 and Fig. 2). The regression outcomes also showed the Akaike information criterion of the Poisson model (AIC $=22294)$ was considerably larger than the AIC of the NB model (AIC = 2906), which proved that the NB model was a better fit to our data (Table S3).

\section{DISCUSSIONS}

Although the existing research has revealed that the long-time exposure to ambient air pollution increases the death risk of COVID-19, our analysis offers scientific understanding to demonstrate that people are more susceptible to COVID-19 if they are chronically exposed to excessive air pollution.

Among all air pollutants that are commonly monitored in Chinese cities, $\mathrm{PM}_{2.5}$ and $\mathrm{NO}_{2}$ are found to be strongly positively correlated with the incidence of COVID-19. This inferential conclusion agrees with many previous studies that seek to attest the statistical relationship between exposure and disease morbidity. Nevertheless, our analysis results show that human $\mathrm{O}_{3}$ exposure is negatively correlated to COVID-19 morbidity. There have been many conflicting conclusions on how $\mathrm{O}_{3}$ exposure affects the occurrence of cardiac and respiratory disease. For instance, a parallel study performed by Wong et al. (2002) shows that while short-term human $\mathrm{O}_{3}$ exposure level is positively associated with daily hospital admissions for cardiovascular disease in London, a negative association is reported in Hong Kong. Consequently, they postulate that Hong Kong residents are more adapted to ozone exposure because their diet contains a high level of antioxidants and air conditioners are often used in compact, poor-ventilated spaces. On the other hand, seasonal variations of the ozone level may have distinct impacts on human health. A cohort study conducted in the Midwest and the Eastern United States demonstrates a negative but nonsignificant association of $\mathrm{O}_{3}$ concentration with mortality (Dockery et al.,1993), while a re-analysis of the data reveals a positive and significant exposure-mortality correlation during warm seasons (Krewski et al., 2003).

Another interesting fact that $\mathrm{SO}_{2}$ and $\mathrm{CO}$ do not share significant associations with COVID-19 morbidity may be attributed to the declining $\mathrm{SO}_{2}$ and $\mathrm{CO}$ emissions in China. This speculation is well supported by empirical observations that find weak correlations between $\mathrm{SO}_{2}, \mathrm{CO}$ exposure and cause-specific mortality when people are exposed to moderate $\mathrm{SO}_{2}$ and $\mathrm{CO}$ concentrations (Townsend and Maynard, 2002; Filleul et al., 2005; Beelen et al., 2008; Dong et al., 2012).

There are a few limitations worth noting in this study: First, the use of observational data from weather stations and pollution monitoring stations may introduce biases since it only demonstrates 
the small-scale meteorological and air pollution dynamics. Instead, satellite data may provide credible estimates concerning the area-wide air quality levels and weather variables. Second, we recognize that our scientific findings may only accumulate to the epidemiological knowledge of COVID-19 within a restricted geographic context, that said, the statistical inferences may vary with widely varying environments in different countries, being altered by their economic status, long-term air pollution exposure levels, etc. Third, giving that the annual mean concentrations of some pollutants are negatively or insignificantly correlated with COVID-19 morbidity, we believe that more importance should be attached to the specification of long-term air pollution exposure. Presumably, for the long-term effects of air pollution, the cumulative dose, seasonal-specific indicators, or composite air pollution indicators may be more decisive in influencing the outcomes of COVID-19. Fourth, our effect estimation could potentially suffer from unmeasured confounding errors. For example, many lifestyle and health risk factors (e.g., body mass index) are often not measured in China at the prefecture level. This means additional analyses might be needed to verify whether unmeasured confounding creates bias to the analysis. Last but not least, the most important caveat of this study is the ecological nature of the analysis. For this reason, our interpretation of the findings should not be extrapolated to individual levels. Besides, since correlational studies often bear endogeneity problems, it is not legitimate to deduce a causal relationship between long-term air pollution exposure and COVID-19 morbidity unless many more credible laboratory evidences become available.

\section{CONCLUSIONS}

Overall, our study indicates that $\mathrm{NO}_{2}, \mathrm{PM}_{2.5}, \mathrm{PM}_{10}$, and $\mathrm{O}_{3}$ have the strongest correlation with the infection risk of COVID-19. We estimate that a $1 \mu \mathrm{g} \mathrm{m}^{-3}$ decrease of the prolonged annual average concentrations of $\mathrm{NO}_{2}, \mathrm{PM}_{2.5}, \mathrm{PM}_{10}$ and $\mathrm{O}_{3}$ are associated with $4.63 \%, 1.95 \%$, and $0.55 \%$ decrease and $2.05 \%$ increase of infection cases. Moreover, our results remain insensitive to adjustment of confounding variables and to different types of regression models applied. Though we have not found any evidence that supports a significant association between $\mathrm{SO}_{2}, \mathrm{CO}$ and the morbidity of COVID-19, future investigations may be needed to lay insights on the underlying mechanisms of their interactions. Moreover, we believe it is necessary to incorporate laboratory investigations to reveal further how long-term air pollution exposure affects the severity of COVID-19. And finally, we argue that although mandatory temporary control of air pollution emissions can be an effective measure to contain COVID-19 infections, persistent pollution reduction strategies that are executed regularly are much more needed to abate severe consequences of a pandemic of such scale in the future.

\section{ACKNOWLEDGMENTS}

The author(s) disclosed receipt of the following financial support for the research, authorship, and/or publication of this article: This work was supported by the projects of the National Natural Science Foundation of China (No. 51878515, No. 51378399, No. 41331175 and No. 52078389). Dr. Qunshan Zhao has received UK ESRC's on-going support for the Urban Big Data Centre (UBDC) [ES/L011921/1 and ES/S007105/1]. The authors would also want to thank the anonymous reviewers for their insightful comments and suggestions on an earlier version of this manuscript.

\section{DISCLAIMER}

The author(s) declared no potential conflicts of interest with respect to the research, authorship, and/or publication of this article.

\section{SUPPLEMENTARY MATERIAL}

Supplementary data associated with this article can be found in the online version at https://doi.org/10.4209/aaqr.2020.07.0413 


\section{REFERENCES}

Baidu Inc. (2020). Baidu migration server. https://qianxi.baidu.com/2020

Beelen, R., Hoek, G., van den Brandt, P.A., Goldbohm, R.A., Fischer, P., Schouten, L.J., Jerrett, M., Hughes, E., Armstrong, B., Brunekreef, B. (2008). Long-term effects of traffic-related air pollution on mortality in a Dutch cohort (NLCS-AIR study). Environ. Health. Perspect. 116, 196202. https://doi.org/10.1289/ehp.10767

Brook, R., Franklin, B., Cascio, W., Hong, Y., Howard, G., Lipsett, M., Luepker, R., Mittleman, M., Samet, J., Smith Jr, S. (2004). A statement for healthcare professionals from the expert panel on population and prevention science of the American heart association. Circulation 109, 2655-2671. https://doi.org/10.1161/01.CIR.0000128587.30041.C8

Chen, Z., Li, R., Chen, D., Zhuang, Y., Gao, B., Yang, L., Li, M. (2020). Understanding the Causal Influence of Major Meteorological Factors on Ground Ozone Concentrations across China. J. Cleaner Prod. 242, 118498. https://doi.org/10.1016/j.jclepro.2019.118498

China CDC (2020). COVID-19 updates. https://ncov.dxy.cn/ncovh5/view/pneumonia (in Chinese) Contini, D., Costabile, N. (2020). Does air pollution influence COVID-19 outbreaks? Atmosphere 11, 377. https://doi.org/10.3390/atmos11040377

Dockery, D.W., Pope, C.A., 3rd, Xu, X., Spengler, J.D., Ware, J.H., Fay, M.E., Ferris, B.G., Jr, Speizer, F.E. (1993). An association between air pollution and mortality in six U.S. cities. N. Engl. J. Med. 329, 1753-1759. https://doi.org/10.1056/NEJM199312093292401

Dong, G.H., Zhang, P., Sun, B., Zhang, L., Chen, X., Ma, N., Yu, F., Guo, H., Huang, H., Lee, Y.L., Tang, N., Chen, J. (2012). Long-term exposure to ambient air pollution and respiratory disease mortality in Shenyang, China: A 12-year population-based retrospective cohort study. Respiration 84, 360-368. https://doi.org/10.1159/000332930

Engin, A.B., Engin, E.D., Engin, A. (2020). Two important controversial risk factors in Sars-Cov-2 infection: Obesity and smoking. Environ. Toxicol. Pharmacol. 78, 103411-103411. https://doi.org/10.1016/j.etap.2020.103411

Filleul, L., Rondeau, V., Vandentorren, S., Le Moual, N., Cantagrel, A., Annesi-Maesano, I., Charpin, D., Declercq, C., Neukirch, F., Paris, C., Vervloet, D., Brochard, P., Tessier, J.F., Kauffmann, F., Baldi, I. (2005). Twenty five year mortality and air pollution: Results from the French PAARC survey. Occup. Environ. Med. 62, 453-460. https://doi.org/10.1136/oem.2004.014746

Goyal, P., Choi, J.J., Pinheiro, L.C., Schenck, E.J., Chen, R., Jabri, A., Satlin, M.J., Campion, T.R., Nahid, M., Ringel, J.B., Hoffman, K.L., Alshak, M.N., Li, H.A., Wehmeyer, G.T., Rajan, M., Reshetnyak, E., Hupert, N., Horn, E.M., Martinez, F.J., Gulick, R.M., Safford, M.M. (2020). Clinical characteristics of Covid-19 in New York City. N. Engl. J. Med. 382, 2372-2374. https://doi.org/10.1056/NEJMc2010419

Grunig, G., Marsh, L.M., Esmaeil, N., Jackson, K., Gordon, T., Reibman, J., Kwapiszewska, G., Park, S.H. (2014). Perspective: Ambient air pollution: Inflammatory response and effects on the lung's vasculature. Pulm. Circ. 4, 25-35. https://doi.org/10.1086/674902

Guan, W., Ni, Z., Hu, Yu, Liang, W., Ou, C., He, J., Liu, L., Shan, H., Lei, C., Hui, D.S.C., Du, B., Li, L., Zeng, G., Yuen, K.Y., Chen, R., Tang, C., Wang, T., Chen, P., Xiang, J., Li, S., Wang, J.L., et al. (2020). Clinical characteristics of coronavirus disease 2019 in China. N. Engl. J. Med. 382, 17081720. https://doi.org/10.1056/NEJMoa2002032

Hilbe, J.M. (2011). Negative binomial regression. Cambridge University Press.

Hoek, G., Krishnan, R.M., Beelen, R., Peters, A., Ostro, B., Brunekreef, B., Kaufman, J.D. (2013). Long-term air pollution exposure and cardio- respiratory mortality: A review. Environ. Health. 12, 43. https://doi.org/10.1186/1476-069X-12-43

Jiang, X.Q., Mei, X.D., Feng, D. (2016). Air pollution and chronic airway diseases: What should people know and do? J. Thorac. Dis. 8, E31-E40. https://doi.org/10.3978/j.issn.2072-1439.2015.11.50

Jin, Y., Andersson, H., Zhang, S. (2016). Air Pollution Control Policies in China: A Retrospective and Prospects. Int. J. Environ. Res. Public Health 13, 1219. https://doi.org/10.3390/ijerph13121219

Krewski, D., Burnett, R., Goldberg, M., Hoover, B., Siemiatycki, J., Jerrett, M., Abrahamowicz, M., White, W. (2003). Re-analysis of the harvard six-cities study and the American cancer society study of air pollution and mortality. J. Toxicol. Environ. Health Part A 66, 1507-1551. https://doi.org/10.1080/15287390306424 
Li, Q., Guan, X., Wu, P., Wang, X., Zhou, L., Tong, Y., Ren, R., Leung, K.S.M., Lau, E.H.Y., Wong, J.Y., Xing, X., Xiang, N., Wu, Y., Li, C., Chen, Q., Li, D., Liu, T., Zhao, J., Liu, M., et al. (2020). Early transmission dynamics in Wuhan, China, of novel coronavirus-infected pneumonia. N. Engl. J. Med. 382, 1199-1207. https://doi.org/10.1056/NEJMoa2001316

Lipfert, F.W. (2018). Long-term associations of morbidity with air pollution: A catalog and synthesis. J. Air Waste Manage. Assoc. 68, 12-28. https://doi.org/10.1080/10962247.2017.13 49010

Liu, W., Tao, Z. W., Wang, L., Yuan, M. L., Liu, K., Zhou, L., Wei, S., Deng, Y., Liu, J., Liu, H.G., Yang, M., Hu, Y. (2020). Analysis of factors associated with disease outcomes in hospitalized patients with 2019 novel coronavirus disease. Chin. Med. J. 133: 1032-1038. https://doi.org/10.1097/ CM9.0000000000000775

MEP (2020). Air quality data portal. http://pm25.in/ (in Chinese)

National Centers for Environmental Information (NCEI) (2020). ftp://ftp.ncdc.noaa.gov/pub /data/noaa

NBS (National Bureau of Statistics of China) (2012). Tabulation on the 2010 population census of the People's Republic of China, China Statistical Press, Beijing.

NBS (National Bureau of Statistics of China) (2018). China City Statistical Yearbook 2018, China Statistical Publishing House, Beijing.

Ogen, Y. (2020). Assessing nitrogen dioxide $\left(\mathrm{NO}_{2}\right)$ Levels as a contributing factor to coronavirus (COVID-19) fatality. Sci. Total Environ. 726, 138605. https://doi.org/10.1016/j.scitotenv.2020. 138605

Pope, C.A., Burnett, R.T., Thurston, G.D., Thun, M.J., Calle, E.E., Krewski, D., Godleski, J.J. (2004). Cardiovascular mortality and long-term exposure to particulate air pollution: Epidemiological evidence of general pathophysiological pathways of disease. Circulation 109, 71-77. https://doi.org/10.1161/01.CIR.0000108927.80044.7F

Song, C., Wu, L., Xie, Y., He, J., Chen, X., Wang, T., Lin, Y., Jin, T., Wang, A., Liu, Y., Dai, Q., Liu, B., Wang, Y.N., Mao, H. (2017). Air pollution in China: Status and spatiotemporal variations. Environ. Pollut. 227, 334-347. https://doi.org/10.1016/j.envpol.2017.04.075

Townsend, C.L., Maynard, R.L. (2002). Effects on health of prolonged exposure to low concentrations of carbon monoxide. Occup. Environ. Med. 59, 708-711. https://doi.org/10.11 36/oem.59.10.708

Wang, M., Luo, X., Xu, S., Liu, W., Ding, F., Zhang, X., Wang, L., Liu, J., Hu, J., Wang, W. (2019). Trends in smoking prevalence and implication for chronic diseases in China: Serial national cross-sectional surveys from 2003 to 2013. Lancet Respir. Med. 7, 35-45. https://doi.org/10.1 016/S2213-2600(18)30432-6

Wang, T., Xue, L., Brimblecombe, P., Lam, Y.F., Li, L., Zhang, L. (2017). Ozone pollution in China: A review of concentrations, meteorological influences, chemical precursors, and effects. Sci. Total Environ. 575, 1582-1596. https://doi.org/10.1016/j.scitotenv.2016.10.081

Wong, C.M., Atkinson, R.W., Anderson, H.R., Hedley, A.J., Ma, S., Chau, P.Y., Lam, T.H. (2002). A tale of two cities: Effects of air pollution on hospital admissions in Hong Kong and London compared. Environ. Health Perspect. 110, 67-77. https://doi.org/10.1289/ehp.0211067

World Health Organization (WHO) (2006). WHO Air quality guidelines for particulate matter, ozone, nitrogen dioxide and sulfur dioxide: Global update 2005: Summary of risk assessment. World Health Organization. https://apps.who.int/iris/handle/10665/69477

World Health Organization (WHO) (2020). WHO Director-General's opening remarks at the media briefing on COVID-19 - 11 March 2020. https://www.who.int/dg/speeches/detail/whodirector-general-s-opening-remarks-at-the-media-briefing-on-covid-19---11-march-2020

Wu, C., Chen, X., Cai, Y., Xia, J.A., Zhou, X., Xu, S., Huang, H., Zhang, L., Zhou, X., Du, C., Zhang, Y., Song, J., Wang, S., Chao, Y., Yang, Z., Xu, J., Zhou, X., Chen, D., Xiong, W., Xu, L., et al. (2020). Risk factors associated with acute respiratory distress syndrome and death in patients with coronavirus disease 2019 pneumonia in Wuhan, China. JAMA Intern Med. 180, 934-943. https://doi.org/10.1001/jamainternmed.2020.0994

Wu, X., Nethery, R.C., Sabath, B.M., Braun, D., Dominici, F. (2020). Exposure to air pollution and COVID-19 mortality in the United States: A nationwide cross-sectional study. medRxiv 2020.04.05.20054502. https://doi.org/10.1101/2020.04.05.20054502

Young, B.E., Ong, S.W.X., Kalimuddin, S., Low, J.G., Tan, S.Y., Loh, J., Ng, O.T., Marimuthu, K., Ang, 
L.W., Mak, T.M., Lau, S.K. (2020). Epidemiologic features and clinical course of patients infected with SARS-CoV-2 in Singapore. JAMA 323, 1488-1494. https://doi.org/10.1001/jama. 2020.3204

Zhao, Y., Zhao, Z., Wang, Y., Zhou, Y., Ma, Y., Zuo, W. (2020). Single-cell RNA expression profiling of ACE2, the receptor of SARS-CoV-2. Am. J. Respir. Crit. Care Med. 202, 756-759. https://doi.org/10.1164/rccm.202001-0179LE

Zheng, B., Tong, D., Li, M., Liu, F., Hong, C., Geng, G., Li, H., Li, X., Peng, L., Qi, J., Yan, L., Zhang, Y., Zhao, H., Zheng, Y., He, K., Zhang, Q. (2018). Trends in China's anthropogenic emissions since 2010 as the consequence of clean air actions. Atmos. Chem. Phys. 18, 14095-14111. https://doi.org/10.5194/acp-18-14095-2018

Zhou, P., Yang, X.L., Wang, X.G., Hu, B., Zhang, L., Zhang, W., Si, H.R., Zhu, Y., Li, B., Huang, C.L. (2020). A pneumonia outbreak associated with a new coronavirus of probable bat origin. Nature 579, 270-273. https://doi.org/10.1038/s41586-020-2012-7

Zhu, Y., Xie, J., Huang, F., Cao, L. (2020). Association between short-term exposure to air pollution and COVID-19 infection: Evidence from China. Sci. Total Environ. 727, 138704. https://doi.org/ 10.1016/j.scitotenv.2020.138704 